\title{
Changes in gait kinematics and muscle activity in stroke patients wearing various arm slings
}

\author{
Young-In Hwang, Jangwhon Yoon* \\ Department of Physical Therapy, College of Biohealth Science, Hoseo University, Asan, Korea
}

Stroke patients often use various arm slings, but the effects of different slings on the joint kinematics and muscle activity of the arm in the gait have not been investigated. The effects of joint kinematics and muscle activity in the gait were investigated to provide suggestions for gait training for stroke patients. In all, 10 chronic stroke patients were voluntarily recruited. An eight-camera three-dimensional motion analysis system was used to measure joint kinematics while walking; simultaneously, electromyography data were collected for the anterior and posterior deltoids and latissimus dorsi. The amplitude of pelvic rotation on the less-affected side differed significantly among the different arm slings $(P<0.05)$. Changes in the knee kinematics of the less-affected side also differed significantly $(P<0.05)$, while there were no significant differences in the muscle activity of the affected arm. In stroke patients, an extended arm sling is more useful than no sling or a flexed arm sling in terms of the amplitude of the rotation of the less-affected pelvic side in the stance phase while walking. The less-affected knee joint is flexed more without a sling than with any sling. All arm slings support the extension of the contralateral knee.

Keywords: Arm sling, Gait, Stroke patients, Arm swing, Electromyography

\section{INTRODUCTION}

Stroke is a major cause of morbidity worldwide. Approximately 800,000 patients have strokes annually (Lloyd-Jones et al., 2010). Patients with stroke have disabilities that result from paralysis, and most complain of difficulty walking (Jørgensen et al., 1995). Bovonsunthonchai et al. (2012) showed that the affected upper extremity is important for improving the performance and coordination of gait in stroke patients. In addition, the movement of the upper extremity improves the range of motion at the ankle as well as trunk stability (Stephenson et al., 2010).

Stroke patients often develop a subluxation of the shoulder on the affected side, because they can no longer support the weight of their own arm due to paralysis (Griffin, 1986). Consequently, arm slings are often necessary. Stroke patients often use a hemisling. Faghri et al. (1994) stated that use of a hemisling induced flexion synergy patterns of the upper trunk and delayed functional activity. However, few studies have examined how different arm slings, including a hemisling, affect the gait patterns of stroke patients. Reported studies have examined the hemisling in terms of the gait patterns (Yavuzer and Ergin, 2002), balance (Acar and Karatas, 2010), and energy consumption (Han et al., 2011) of stroke patients.

There are various types of arm sling, such as the flexed sling (a single-strap hemisling), extended sling (Bobath sling, Rolyan sling), GivMohr sling (Dieruf et al., 2005), and elastic arm sling (Hwang and An, 2015). The sling supports some of the weight of the arm and simultaneously limits the motion of the upper extremities. Pontzer et al. (2009) suggested that the arms serve as passive mass dampers to decrease the rotation of the torso and head. Lieberman et al. $(2007,2008)$ also held that the arms serve as passive dampers to minimise vertical motion. The trunk and shoulders act as elastic linkages between the pelvis, shoulder girdle, and arms (Pontzer et al., 2009).

Some studies have examined the activities of the arm muscle during walking (Lieberman et al., 2007; Prentice et al., 2001),
${ }^{*}$ Corresponding author: Jangwhon Yoon (i) http://orcid.org/0000-0001-8616-1566 Department of Physical Therapy, College of Biohealth Science, Hoseo University, 79 Hoseo-ro 231beon-gil Baebang-eup, Asan 31496, Korea Tel: +82-41-540-9972, Fax: +82-41-540-9975, E-mail: doraora@gmail.com Received: January 12, 2017 / Accepted: March 31, 2017
This is an Open Access article distributed under the terms of the Creative Commons Attribution Non-Commercial License (http://creativecommons.org/licenses/by-nc/4.0/) which permits unrestricted non-commercial use, distribution, and reproduction in any medium, provided the original work is properly cited. 
while other studies have found that most of the arm swing is passive, while a small torque may actively occur in shoulder rotation (Jackson et al., 1978; Kubo et al., 2004). The muscle activity of the upper extremities is still the subject of debate (Collins et al., 2009; Kubo et al., 2004; Kuhtz-Buschbeck and Jing, 2012). However, the restrictive effects and support provided by various arm slings could have different effects on the muscle activities of the affected arm in stroke patients.

Therefore, we investigated how the muscle activities of the affected arm and kinematic data taken during walking are influenced by flexion-type (hemisling), extension-type (Rolyan sling), and elastic arm slings under elastic tension. We discuss which arm should be used for clinical gait training.

\section{MATERIALS AND METHODS}

\section{Study participants}

In all, 10 patients who had experienced a stroke (male, 5; female, 5) volunteered to participate in this study. Basic demographic information was obtained, including diagnosis, affected side, and postonset changes. The characteristics of the participants are summarized in Table 1. Inclusion criteria were as follows: diagnosis of stroke due to infarction or haemorrhage, score over 21 on the Mini-Mental Status Examination and ability to walk independently or with a cane. Exclusion criteria were as follows: medical problems that affect the gait pattern other than the neurological lesion, bilateral affected limbs or a premorbid or current orthopaedic problem related to the feet. The study was approved by the

Table 1. Characteristics of the participants

\begin{tabular}{lc}
\hline Characteristic & Value \\
\hline Diagnosis & \\
$\quad$ Intracranial hemorrhage & 7 \\
Cerebral infarction & 3 \\
Cerebrovascular accident & 1 \\
Affected side & \\
Left & 5 \\
Right & 5 \\
Gender & \\
Male & 5 \\
Female & 5 \\
Age (yr) & $58.10 \pm 9.20(47-73)$ \\
Height (cm) & $159.2 \pm 6.68(146.9-169.3)$ \\
Weight (kg) & $57.29 \pm 8.14(42-72.6)$ \\
Post onset (mo) & $39.4 \pm 13.7(15-54)$ \\
\hline
\end{tabular}

Values are presented as number or mean \pm standard deviation (range). institutional review board at Hoseo University. All participants understood the procedures used in this study and gave written informed consent before participation.

\section{Gait kinematics}

An eight-camera three-dimensional motion analysis system (Vicon, Fareham, UK) was used to evaluate the transverse and sagittal kinematics of both lower extremities (pelvis, hips, knees, and ankles) at a sampling rate of $100 \mathrm{~Hz}$ (Yoon et al., 2016). To evaluate the kinematics of the lower extremities, 16 markers were attached to the subjects bilaterally, as follows: the anterior and posterior superior iliac spines, the lower lateral $1 / 4$ surface of the thigh, the lateral epicondyle of the knee, the lateral malleolus, the lower $1 / 3$ of the shank, the second metatarsal head, and the posterior calcaneus. To minimise error, one experienced researcher attached all of the markers (Yoon et al., 2016).

\section{Muscle activity}

The activities of the anterior deltoid, posterior deltoid, and latissimus dorsi muscles were recorded using a Delsys Trigno Wireless EMG system (Delsys, Natick, MA, USA), which was synchronised with a Vicon Motion System. To compare muscle activity and other data, subjects performed a maximal normalisation contraction of each muscle on the affected side 3 times and obtained acceptable signals. The surface electrode placement for the three muscles was as follows: anterior deltoid, within an elongated oval below the lateral end of the clavicle; posterior deltoid, two fingerbreadths behind the acromion; and latissimus dorsi, below the inferior angle of the scapula (Perotto et al., 2011; Xu et al., 2014). Before the electrodes were applied, the skin was shaved and wiped with a cotton swab soaked in alcohol.

\section{Procedures}

Before the procedure, the investigator demonstrated a walk in front of the subjects. A seat was available for rest before and after each test. The activities of the anterior and posterior deltoid and latissimus dorsi muscles of all subjects were monitored by surface electromyography (EMG) while walking. The subjects prepared for their walk while standing, and performed the walk under four conditions in random order: no sling, a flexed sling (a hemisling), an extended arm sling (Rolyan sling), and an elastic arm sling (Fig. 1). All subjects performed each test twice and were allowed 2 min between tests. The elastic arm sling designed by Hwang and An (2015) was employed, using the green elastic tension band, as in their study. One experienced researcher adjusted the 

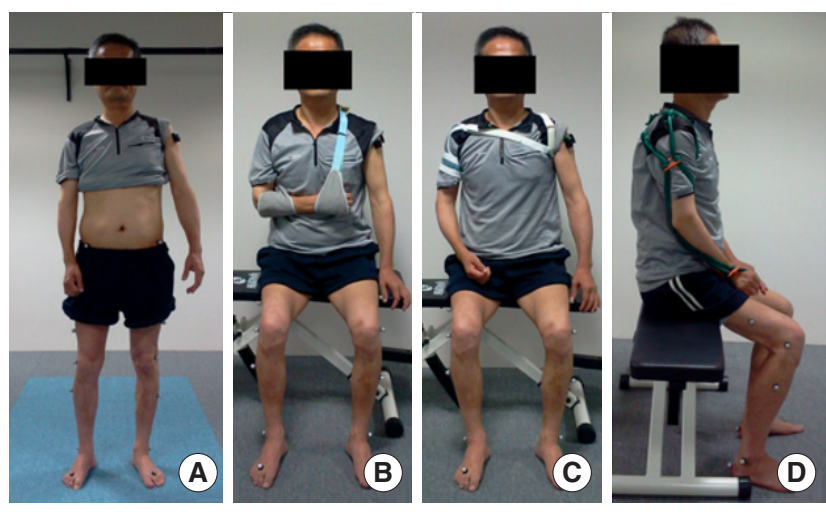

Fig. 1. The conditions of the various arm slings: $(A)$ none, $(B)$ a flexed type, $(C)$ an extended type, and (D) an elastic type.

elastic arm sling to control the tension so that it was comfortable for the subjects.

\section{Data analysis}

Motion data were captured and the marker trajectories were post-processed using Nexus 1.7 software (Vicon, Fareham, UK). The kinematics of the pelvis and hip were defined as rotation in the transverse plane in the stance phase. The amplitude of the pelvic and hip motion was calculated as the maximum value minus the minimum value. The ranges of angles of the hips, knees, and ankles were determined for the affected and non-affected sides in the stance phase. EMG signals were sampled at 2,000 $\mathrm{Hz}$ and filtered at $20-450 \mathrm{~Hz}$. The root mean square values of the signals were calculated. For normalisation, EMG data were reported as a percentage of maximal voluntary contraction.

\section{Statistical analysis}

Friedman test (SPSS ver. 20.0, SPSS Inc., Chicago, IL, USA) was used to assess the effects of wearing the different arm slings on the kinematic data during the gait and muscle activities of the affected arm. Post hoc analyses were conducted using the Wilcoxon matched-pairs signed-rank test. The level of significance was set at $P<0.05$.

\section{RESULTS}

The results are given as the degrees of pelvic rotation and hip, knee, and ankle sagittal angle using the different arm slings. In the stance phase, the amplitude of pelvic rotation significantly $(P<0.05)$ differed among the slings on the less-affected side but not on the affected side (Table 2). Specifically, the rotation significantly differed between the extended arm sling and both the flexed arm sling and no sling $(P<0.05)$ (Fig. 2). There were no differences in the angles of the hip, knee, and ankle on the two sides, but the minimum knee angle on the less-affected side significantly differed between all slings and having no sling (Table 2, Fig. 3).

The activities of the anterior and posterior deltoid and latissimus dorsi muscles did not differ significantly while walking using the various arm slings (Table 3).

\section{DISCUSSION}

We investigated the effects of a flexed arm sling, extended arm sling, elastic arm sling, and no arm sling on kinematic data during gait, and the muscle activity of the arm in stroke patients.

The amplitude of pelvic rotation on the less-affected side significantly differed between the extended sling and both the flexed sling and no sling in the stance phase. In healthy people, the standard range of pelvic amplitude is about $10^{\circ}$, and maximal forward and backward rotation are about $5^{\circ}$ during initial contact and terminal stance (Perry and Burnfield, 2010). In our study, the rotation on the less-affected side was about $7^{\circ}$ without an arm sling and with a flexed arm sling, but was approximately $12^{\circ}$ with an extended arm sling. By comparison, there was no significant difference between the elastic arm sling and the other slings. We hypothesised that the sling's flexible elastic material plays a role similar to that of muscle, but further studies are needed.

The extended arm sling may provide stability to the contralateral shoulder, increasing the amplitude of pelvic rotation on the less-affected side. Indeed, some researchers have found that using additional arm weights increases shoulder stability and pelvic rotation (Yoon et al., 2016). In a study that compared the flexed and extended arm slings, the latter did not interrupt the arm swing, which plays an important role in counterbalancing the movement of the pelvis and lower extremities (Zehr and Duysens, 2004). In addition, the alignment of the glenohumeral joint in the paretic arm may be assisted by the extended arm sling (Dieruf et al., 2005).

A previous study of the elastic arm sling found that while it significantly improved walking velocity and both step and stride length, there was no significant difference in pelvic rotation amplitude (Hwang and An, 2015). We postulated that the elastic tension would provide flexibility as well as stability for support. Therefore, an elastic arm sling with tension may aid gait training in stroke patients.

Yavuzer and Ergin (2002) found that the kinematics of arm ro- 
Table 2. Comparison of the kinematics of the pelvis and lower extremities using the various arm slings $(P<0.05)$

\begin{tabular}{|c|c|c|c|c|c|}
\hline Angle & None & A flexed arm sling & An extended arm sling & An elastic arm sling & $P$-value \\
\hline \multicolumn{6}{|c|}{ Pelvic rotation amplitude $\left(^{\circ}\right)$ at stance phase } \\
\hline Affected & $8.81 \pm 3.99$ & $8.88 \pm 2.89$ & $13.89 \pm 9.04$ & $9.36 \pm 6.15$ & 0.753 \\
\hline Less-affected & $7.99 \pm 2.29$ & $7.40 \pm 1.89$ & $12.35 \pm 5.84$ & $10.72 \pm 5.17$ & $0.038^{*}$ \\
\hline \multicolumn{6}{|l|}{ Hip angle $\left(^{\circ}\right)$} \\
\hline \multicolumn{6}{|l|}{ Affected } \\
\hline Maximum & $32.24 \pm 7.93$ & $32.37 \pm 7.34$ & $31.63 \pm 7.31$ & $31.34 \pm 6.43$ & 0.668 \\
\hline Minimum & $5.04 \pm 9.51$ & $6.57 \pm 9.21$ & $4.27 \pm 7.80$ & $4.51 \pm 8.32$ & 0.218 \\
\hline \multicolumn{6}{|l|}{ Less-affected } \\
\hline Maximum & $35.81 \pm 7.70$ & $38.34 \pm 7.73$ & $37.05 \pm 7.44$ & $38.06 \pm 6.71$ & 0.516 \\
\hline Minimum & $5.81 \pm 9.69$ & $3.99 \pm 9.81$ & $4.08 \pm 9.78$ & $3.41 \pm 10.08$ & 0.668 \\
\hline \multicolumn{6}{|l|}{ Knee angle $\left({ }^{\circ}\right)$} \\
\hline \multicolumn{6}{|l|}{ Affected } \\
\hline Maximum & $42.07 \pm 12.11$ & $38.73 \pm 13.02$ & $38.71 \pm 10.88$ & $38.59 \pm 10.77$ & 0.696 \\
\hline Minimum & $7.36 \pm 6.99$ & $4.75 \pm 7.76$ & $4.43 \pm 6.45$ & $5.71 \pm 8.51$ & 0.410 \\
\hline \multicolumn{6}{|l|}{ Less-affected } \\
\hline Maximum & $54.27 \pm 16.43$ & $58.98 \pm 12.97$ & $57.28 \pm 13.36$ & $60.04 \pm 13.82$ & 0.392 \\
\hline Minimum & $17.99 \pm 8.38$ & $14.86 \pm 8.59$ & $15.65 \pm 8.60$ & $15.57 \pm 8.07$ & $0.033^{*}$ \\
\hline \multicolumn{6}{|l|}{ Ankle angle $\left({ }^{\circ}\right)$} \\
\hline \multicolumn{6}{|l|}{ Affected } \\
\hline Maximum & $18.21 \pm 4.62$ & $18.49 \pm 5.83$ & $16.87 \pm 5.63$ & $17.57 \pm 4.64$ & 0.266 \\
\hline Minimum & $-6.06 \pm 12.02$ & $-9.18 \pm 7.35$ & $-7.91 \pm 9.99$ & $-7.91 \pm 11.04$ & 0.668 \\
\hline \multicolumn{6}{|l|}{ Less-affected } \\
\hline Maximum & $25.35 \pm 7.42$ & $26.37 \pm 9.19$ & $26.89 \pm 10.10$ & $27.67 \pm 8.65$ & 0.392 \\
\hline Minimum & $2.80 \pm 9.51$ & $1.54 \pm 8.13$ & $0.74 \pm 8.74$ & $1.35 \pm 9.76$ & 0.516 \\
\hline
\end{tabular}

Values are presented as mean \pm standard deviation.

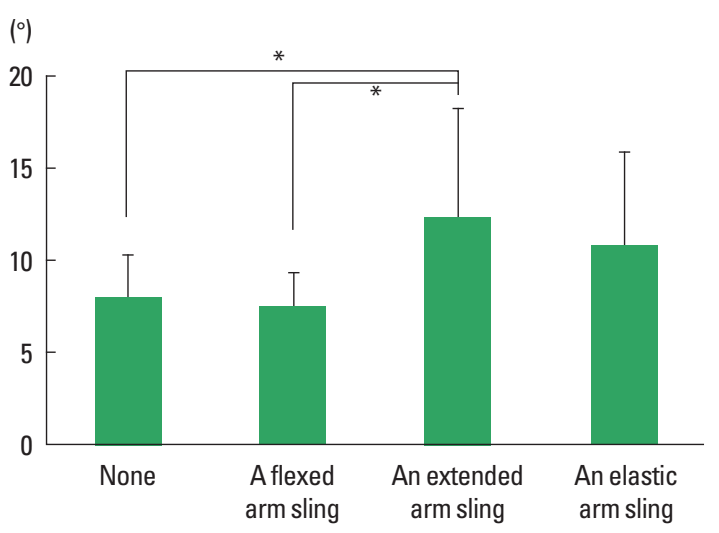

Fig. 2. Pelvic rotation amplitude in less-affected side at stance phase $\left({ }^{*} P<0.05\right)$.

tation did not significantly differ between using a flexed arm sling and not using one. Our results are in agreement. The flexion pattern of the upper extremity did not differ from kinematic data without an arm sling. However, research has shown that a flexed arm sling can increase walking speed, double the stance period, and increase weight-bearing on the paretic side (Yavuzer and

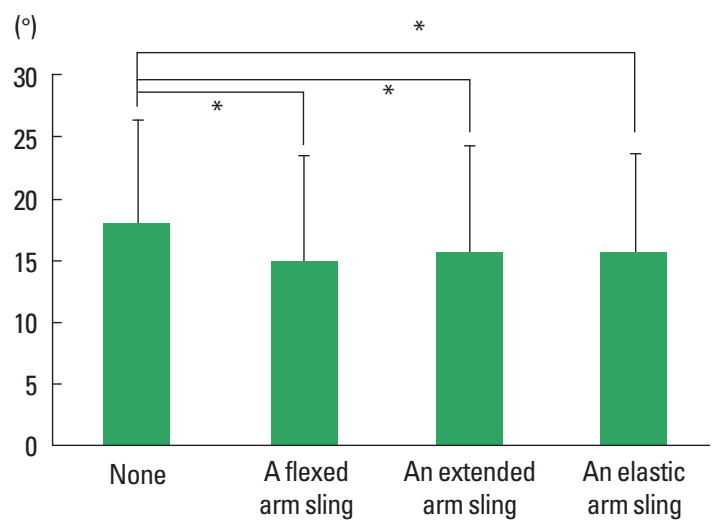

Fig. 3. Changes of the less-affected knee kinematics at minimal value ( $\left.{ }^{*} P<0.05\right)$.

Ergin, 2002). The kinematics of the less-affected knee differed significantly between each sling and not using one. The stability of the contralateral shoulder with the slings might help to extend the knee on the less-affected side. Anatomically, if we consider the spiral line of fascial connections to the rhomboids major and minor, the lower part of the serratus anterior, the external oblique, 
Table 3. Comparison of the muscle activities in the affected side among the several arm slings $(P<0.05)$

\begin{tabular}{lccccc}
\hline Affected side & None & A flexed arm sling & An extended arm sling & An elastic arm sling & $P$-value \\
\hline AD & $8.62 \pm 6.32$ & $7.59 \pm 5.78$ & $8.24 \pm 5.02$ & $8.25 \pm 4.03$ & 0.218 \\
PD & $24.61 \pm 18.64$ & $22.36 \pm 16.24$ & $25.84 \pm 19.50$ & $24.94 \pm 19.18$ & 0.530 \\
LD & $34.23 \pm 19.27$ & $37.66 \pm 29.01$ & $35.96 \pm 27.64$ & $31.30 \pm 18.26$ & 0.668 \\
\hline
\end{tabular}

Values are presented as mean \pm standard deviation.

$A D$, anterior deltoid; $P D$, posterior deltoid; $L D$, latissimus dorsi.

and the opposite of the internal oblique (Myers, 2014), then all of the arm slings might enhance the stability of the trunk, which in turn might enhance knee extension. In addition, the vertical movement produced by the restrained arm swing using an arm sling increases knee extension (minimal knee kinematics), because lower swings of the counteracting arm result in higher vertical moment (Li et al., 2001). However, a recent study found that flexed and extended arm slings had no effect on balance, including weight asymmetry patterns, although the stroke patients were standing in that investigation (Sohn et al., 2015). In addition, unlike our study, those researchers applied a Bobath sling to both the affected and unaffected sides.

We investigated the effects of changes in the muscle activity of the swinging arm on stability during walking while wearing flexed, extended, and elastic arm slings. There were no differences in muscle flexion or extension of the affected arm. A reciprocal arm swing is a natural motion during walking (Perry and Burnfield, 2010), and we inferred that an arm sling does not interrupt the automatic arm swing response. In the neural system, a locomotor pattern generator may control arm swing (Jackson et al., 1978). Gutnik et al. (2005) compared arms with simple and unrestrained pendulums. Symans and Constantinou (1999) considered the passive arm swing to act as a mass damper system that transfers energy from the swinging legs and spinal column. However, Ballesteros et al. (1965) suggested that the muscle activity in the shoulder plays an important role in maintaining stability while walking and especially while running.

This study had some limitations. The sample size was too small to normalise the kinematic data, and arm swing motion with different arm slings was not evaluated. Muscle activity was not compared between the anteversion and retroversion of the arm swing. We evaluated the kinematic data of the lower extremities while walking and wearing various arm slings. Further studies should investigate the effects of arm slings to research arm kinematics and arm swing.

In stroke patients, an extended arm sling has a greater effect on pelvic rotation on the less-affected side than no sling or a flexed arm sling in the stance phase during walking. Without a sling, the less-affected knee joint is flexed more than with any sling. All arm slings tested supported the extension of the contralateral knee.

\section{CONFLICT OF INTEREST}

No potential conflict of interest relevant to this article was reported.

\section{ACKNOWLEDGMENTS}

This study was funded from Hoseo University, Asan, South Korea (2016-0062). Thanks to the Haundae Baek and Seo-ho Hopstital, we could investigate this study.

\section{REFERENCES}

Acar M, Karatas GK. The effect of arm sling on balance in patients with hemiplegia. Gait Posture 2010;32:641-644.

Ballesteros ML, Buchthal F, Rosenfalck P. The pattern of muscular activity during the arm swing of natural walking. Acta Physiol Scand 1965; 63:296-310.

Bovonsunthonchai S, Hiengkaew V, Vachalathiti R, Vongsirinavarat M, Tretriluxana J. Effect of speed on the upper and contralateral lower limb coordination during gait in individuals with stroke. Kaohsiung J Med Sci 2012;28:667-672.

Collins SH, Adamczyk PG, Kuo AD. Dynamic arm swinging in human walking. Proc Biol Sci 2009;276:3679-3688.

Dieruf K, Poole JL, Gregory C, Rodriguez EJ, Spizman C. Comparative effectiveness of the GivMohr sling in subjects with flaccid upper limbs on subluxation through radiologic analysis. Arch Phys Med Rehabil 2005;86:2324-2329.

Faghri PD, Rodgers MM, Glaser RM, Bors JG, Ho C, Akuthota P. The effects of functional electrical stimulation on shoulder subluxation, arm function recovery, and shoulder pain in hemiplegic stroke patients. Arch Phys Med Rehabil 1994;75:73-79.

Griffin JW. Hemiplegic shoulder pain. Phys Ther 1986;66:1884-1893. 
Gutnik B, Mackie H, Hudson G, Standen C. How close to a pendulum is human upper limb movement during walking? Homo 2005;56:35-49.

Han SH, Kim T, Jang SH, Kim MJ, Park SB, Yoon SI, Choi BK, Lee MY, Lee $\mathrm{KH}$. The effect of an arm sling on energy consumption while walking in hemiplegic patients: a randomized comparison. Clin Rehabil 2011;25:36-42.

Hwang YI, An DH. Immediate effects of an elastic arm sling on walking patterns of chronic stroke patients. J Phys Ther Sci 2015;27:35-37.

Jackson KM, Joseph J, Wyard SJ. A mathematical model of arm swing during human locomotion. J Biomech 1978;11:277-289.

Jørgensen HS, Nakayama H, Raaschou HO, Olsen TS. Recovery of walking function in stroke patients: the Copenhagen Stroke Study. Arch Phys Med Rehabil 1995;76:27-32.

Kubo M, Wagenaar RC, Saltzman E, Holt KG. Biomechanical mechanism for transitions in phase and frequency of arm and leg swing during walking. Biol Cybern 2004;91:91-98.

Kuhtz-Buschbeck JP, Jing B. Activity of upper limb muscles during human walking. J Electromyogr Kinesiol 2012;22:199-206.

Li Y, Wang W, Crompton RH, Gunther MM. Free vertical moments and transverse forces in human walking and their role in relation to armswing. J Exp Biol 2001;204(Pt 1):47-58.

Lloyd-Jones D, Adams RJ, Brown TM, Carnethon M, Dai S, De Simone G, Ferguson TB, Ford E, Furie K, Gillespie C, Go A, Greenlund K, Haase N, Hailpern S, Ho PM, Howard V, Kissela B, Kittner S, Lackland D, Lisabeth L, Marelli A, McDermott MM, Meigs J, Mozaffarian D, Mussolino M, Nichol G, Roger VL, Rosamond W, Sacco R, Sorlie P, Roger VL, Thom T, Wasserthiel-Smoller S, Wong ND, Wylie-Rosett J; American Heart Association Statistics Committee and Stroke Statistics Subcommittee. Heart disease and stroke statistics--2010 update: a report from the American Heart Association. Circulation 2010;121:e46-215.

Lieberman DE, Bramble DM, Raichlen DA. Integration of the head and forelimb in bipedal hominids. ICVM-8 abstracts. J Morphol 2007;268: 1099.

Lieberman DE, Bramble DM, Raichlen DA, Whitcome KW. Functional, developmental and moprhological integration: the case of the head and forelimb in bipedal hominids. Am J Phys Anthropol 2008;46:140141.

Myers TW. Anatomy trains: myofascial meridians for manual and movement therapists. 3rd ed. Edinburgh: Elsevier; 2014.

Perotto AO, Delagi EF, Iazzetti J, Morrison D. Anatomical guide for the electromyographer: the limbs and trunk. 5th ed. Springfield (IL): Charles C. Thomas Publisher; 2011.

Perry J, Burnfield JM. Gait analysis: normal and pathological function. 2nd ed. Thorofare: SLACK Incoporated; 2010.

Pontzer H, Holloway JH 4th, Raichlen DA, Lieberman DE. Control and function of arm swing in human walking and running. J Exp Biol 2009;212(Pt 4):523-534.

Prentice SD, Patla AE, Stacey DA. Artificial neural network model for the generation of muscle activation patterns for human locomotion. J Electromyogr Kinesiol 2001;11:19-30.

Sohn MK, Jee SJ, Hwang P, Jeon Y, Lee H. The effects of shoulder slings on balance in patients with hemiplegic stroke. Ann Rehabil Med 2015;39:986-994.

Stephenson JL, De Serres SJ, Lamontagne A. The effect of arm movements on the lower limb during gait after a stroke. Gait Posture 2010;31:109115.

Symans MD, Constantinou MC. Semi-active control systems for seismic protection of structures: a state-of-the-art review. Eng Struct 1999;21: 469-487.

Xu X, McGorry RW, Lin JH. A regression model predicting isometric shoulder muscle activities from arm postures and shoulder joint moments. J Electromyogr Kinesiol 2014;24:419-429.

Yavuzer G, Ergin S. Effect of an arm sling on gait pattern in patients with hemiplegia. Arch Phys Med Rehabil 2002;83:960-963.

Yoon J, Park J, Park K, Jo G, Kim H, Jang W, Kim J7, Youn J, Oh ES, Kim $\mathrm{HT}$, Youm $\mathrm{CH}$. The effects of additional arm weights on arm-swing magnitude and gait patterns in Parkinson's disease. Clin Neurophysiol 2016;127:693-697.

Zehr EP, Duysens J. Regulation of arm and leg movement during human locomotion. Neuroscientist 2004;10:347-361. 